Supporting Information for

\title{
BDPA-Doped Polystyrene Beads as Polarization Agents for DNP-NMR
}

\author{
Yunzhi Zhang, Phillip J. Baker, and Leah B. Casabianca \\ Department of Chemistry, Clemson University, Clemson, SC, USA.
}

\section{Complete References:}

(8) Nelson, S. J.; Kurhanewicz, J.; Vigneron, D. B.; Larson, P. E. Z.; Harzstark, A. L.; Ferrone, M.; van Criekinge, M.; Chang, J. W.; Bok, R.; Park, I.; Reed, G.; Carvajal, L.; Small, E. J.; Munster, P.; Weinberg, V. K.; Ardenkjaer-Larsen, J. H.; Chen, A. P.; Hurd, R. E.; Odegardstuen, L. I.; Robb, F. J.; Tropp, J.; Murray, J. A. Metabolic Imaging of Patients with Prostate Cancer Using Hyperpolarized [1-C-13]Pyruvate. Sci. Transl. Med. 2013, 5, 198 ra108.

(13) Vitzthum, V.; Miéville, P.; Carnevale, D.; Caporini, M. A. ; Gajan, D. ; Copéret, C.; Lelli, M.; Zagdun, A.; Rossini, A. J.; Lesage, A.; Emsley, L.; Bodenhausen, G. Dynamic nuclear polarization of quadrupolar nuclei using cross polarization from protons: surface-enhanced aluminium-27 NMR. Chem. Commun. 2012, 48, 1988-1990.

(14) Lelli, M.; Gajan, D.; Lesage, A.; Caporini, M. A.; Vitzthum, V.; Miéville, P.; Héroguel, F.; Rascón, F.; Roussey, A.; Thieuleux, C.; Boualleg, M.; Veyre, L.; Bodenhausen, G.; Copéret, C.; Emsley, L. Fast Characterization of Functionalized Silica Materials by Silicon-29 SurfaceEnhanced NMR Spectroscopy Using Dynamic Nuclear Polarization. J. Am. Chem. Soc. 2011, 133, 2104-2107.

(15) Lafon, O.; Lilly Thankamony, A. S.; Kobayashi, T.; Carnevale, D.; Vitzthum, V.; Slowing, I. I.; Kandel, K.; Vezin, H.; Amoureux, J.-P.; Bodenhausen, G.; Pruski, M. Mesoporous Silica Nanoparticles Loaded With Surfactant: Low Temperature Magic Angle Spinning C and Si NMR Enhanced by Dynamic Nuclear Polarization. J. Phys. Chem. C. 2013, 117, 1375-1382.

(20) Aptekar, J. W.; Cassidy, M. C.; Johnson, A. C.; Barton, R. A.; Lee, M.; Ogier, A. C.; Vo, C.; Anahtar, M. N.; Ren, Y.; Bhatia, S. N.; Ramanathan, C.; Cory, D. G.; Hill, A. L.; Mair, R. W.; Rosen, M. S.; Walsworth, R. L.; Marcus, C. M. Silicon Nanoparticles as Hyperpolarized Magnetic Resonance Imaging Agents. ACS Nano 2009, 3, 4003-4008.

(31) Can, T. V.; Caporini, M. A.; Mentink-Vigier, F.; Corzilius, B.; Walish, J. J.; Rosay, M.; Maas, W. E.; Baldus, M.; Vega, S.; Swager, T. M.; Griffin, R. G. Overhauser effects in insulating solids. J. Chem. Phys. 2014, 141, 064202.

(35) van Heeswijk, R. B.; Uffmann, K.; Comment, A.; Kurdzesau, F.; Perazzolo, C.; Cudalbu, C.; Jannin, S.; Konter, J. A.; Hautle, P.; van den Brandt, B.; Navon, G.; van der Klink, J. J.; Gruetter, R. Hyperpolarized Lithium-6 as a Sensor of Nanomolar Contrast Agents. Magn. Reson. Med. 2009, 61, 1489-1493. 


\section{Additional Information:}

In supplementary Figures S1-S4 we present the results of control dissolution DNP experiments under standard conditions with well-known dissolution DNP radicals. These figures illustrate the range of enhancement factors that can be obtained using dissolution DNP. Enhancement factors may be heavily influenced by several experimental parameters, such as the time required for sample shuttling from the DNP polarizer to the NMR magnet, and slight changes in temperature at which the DNP polarization transfer is performed, and are therefore not generally reproducible among different labs or even on different days. The experiments in Figures S1-S3 were done with the 4-hydroxy-TEMPO radical, which is a popular water-soluble DNP polarization agent, at different concentrations and in the presence and absence of DMSO cosolvent. Polarization buildup curves indicate that the polarization buildup with TEMPO was complete in $\sim 20$ minutes. In Figure S4, we present the results of a dissolution DNP experiment using BDPA to hyperpolarize neat toluene, which self-glasses. 

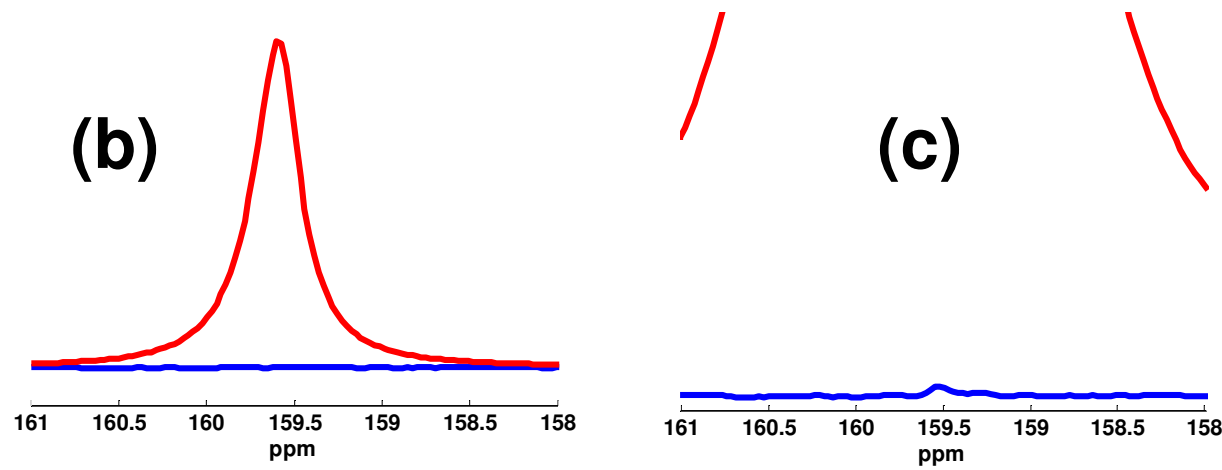

Figure S1. (a) Series of ${ }^{13} \mathrm{C}$ NMR spectra of ${ }^{13} \mathrm{C}$-labeled urea generated by a succession of small tip angle pulses following a dissolution DNP experiment. A total of 200 spectra were acquired, but for clarity only every 4 th spectrum is shown. The sample was ${ }^{13} \mathrm{C}$-urea dissolved in 60:40 DMSO: $\mathrm{D}_{2} \mathrm{O}$ containing $41 \mathrm{mM}$ 4-hydroxy TEMPO. $100 \mu \mathrm{L}$ of the sample was polarized at $94.030 \mathrm{GHz}$ at $100 \mathrm{~mW}$ power and $1.57 \mathrm{~K}$ for 22 minutes, followed by dissolution with $4 \mathrm{~mL}$ of water. Successive spectra were acquired $1 \mathrm{~s}$ apart. (b) Comparison of thermal and DNPenhanced signal. (c) Same as in (b) but zoomed in so that the height of the thermal signal is visible. The enhancement factor is $\sim 2000$. 

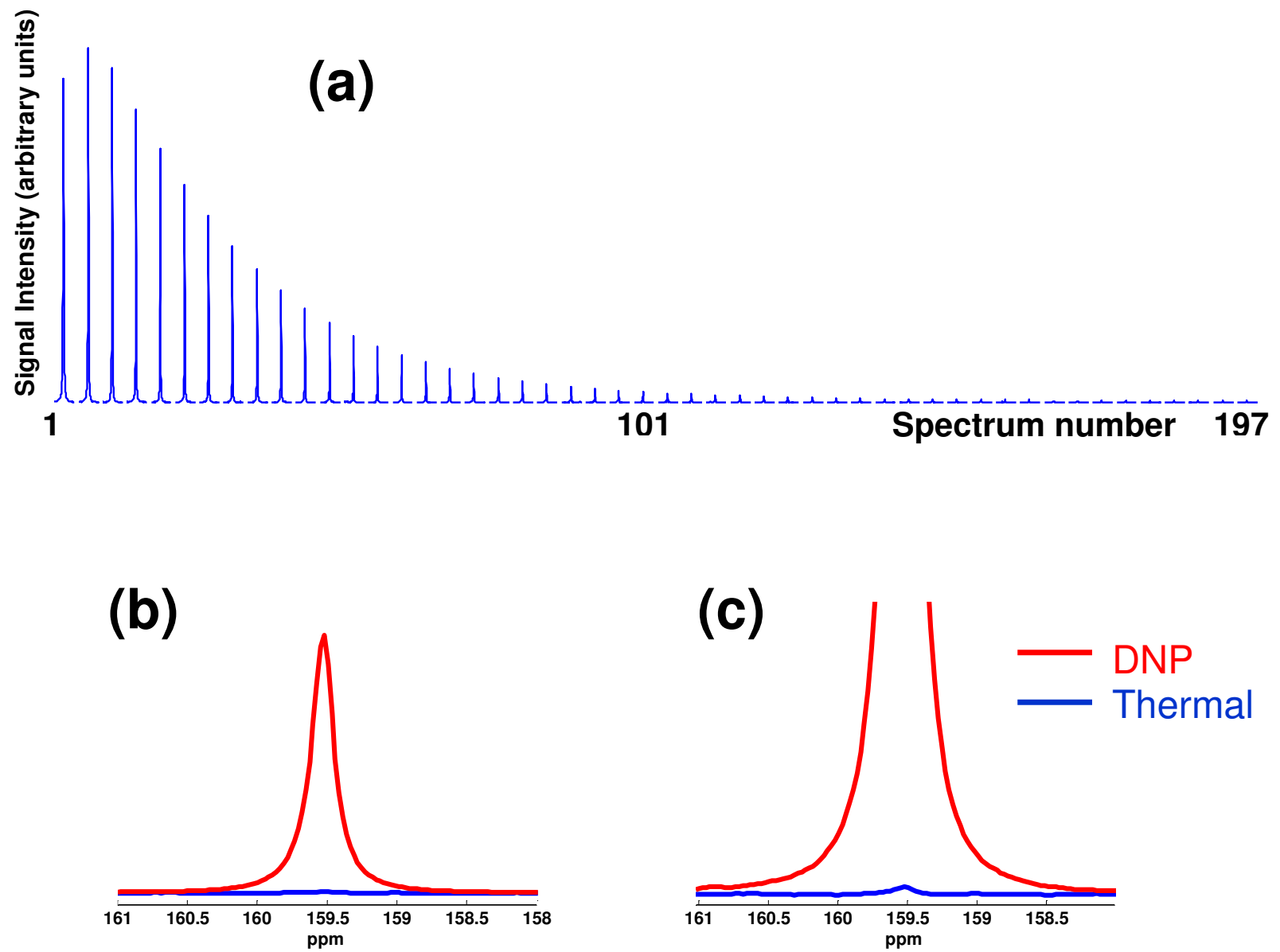

Figure S2. (a) Series of ${ }^{13} \mathrm{C}$ NMR spectra of ${ }^{13} \mathrm{C}$-labeled urea generated by a succession of small tip angle pulses following a dissolution DNP experiment. A total of 200 spectra were acquired, but for clarity only every 4 th spectrum is shown. The sample was ${ }^{13} \mathrm{C}$-urea dissolved in $\mathrm{H}_{2} \mathrm{O}$ containing $39 \mathrm{mM}$ 4-hydroxy TEMPO. $100 \mu \mathrm{L}$ of the sample was polarized at $94.030 \mathrm{GHz}$ at $100 \mathrm{~mW}$ power and $1.60 \mathrm{~K}$ for 30 minutes, followed by dissolution with $4 \mathrm{~mL}$ of water. Successive spectra were acquired $1 \mathrm{~s}$ apart. (b) Comparison of thermal and DNP-enhanced signal. (c) Same as in (b) but zoomed in so that the height of the thermal signal is visible. The enhancement factor is 211 . 


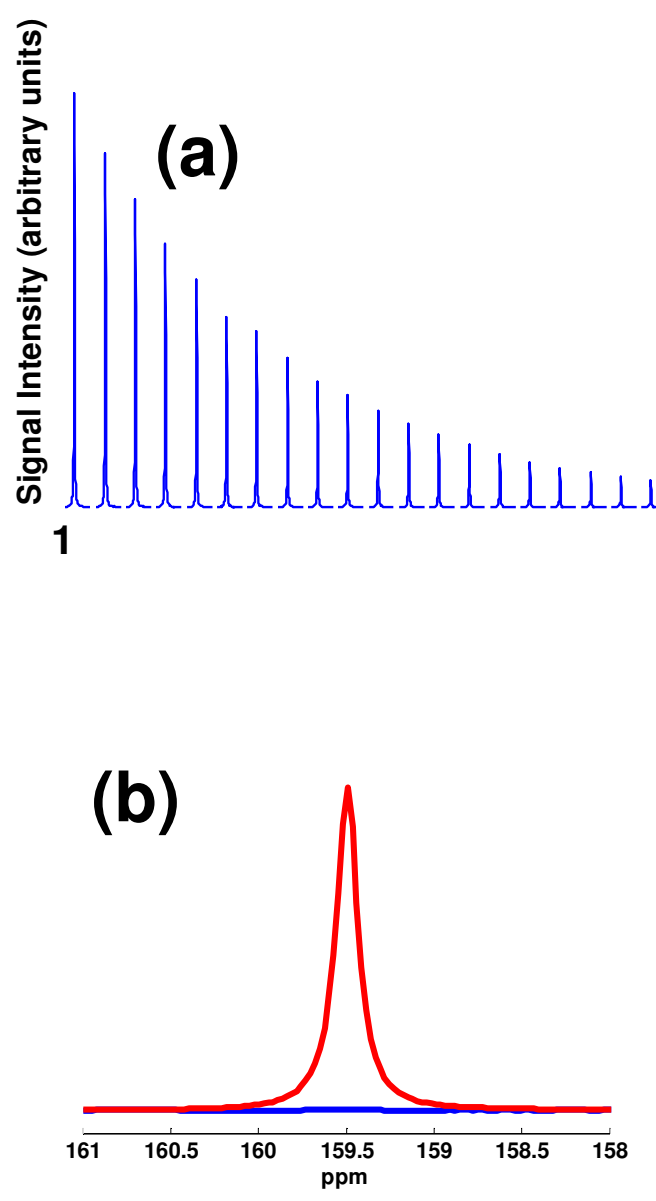

Figure S3. (a) Series of ${ }^{13} \mathrm{C}$ NMR spectra of ${ }^{13} \mathrm{C}$-labeled urea generated by a succession of small tip angle pulses following a dissolution DNP experiment. A total of 200 spectra were acquired, but for clarity only every 4 th spectrum is shown. The sample was ${ }^{13} \mathrm{C}$-urea dissolved in $\mathrm{H}_{2} \mathrm{O}$ containing $1.7 \mathrm{mM}$ 4-hydroxy TEMPO. $100 \mu \mathrm{L}$ of the sample was polarized at $94.030 \mathrm{GHz}$ at $100 \mathrm{~mW}$ power and $1.61 \mathrm{~K}$ for 30 minutes, followed by dissolution with $4 \mathrm{~mL}$ of water. Successive spectra were acquired $1 \mathrm{~s}$ apart. (b) Comparison of thermal and DNP-enhanced signal. (c) Same as in (b) but zoomed in so that the height of the thermal signal is visible. The enhancement factor is 225 . 

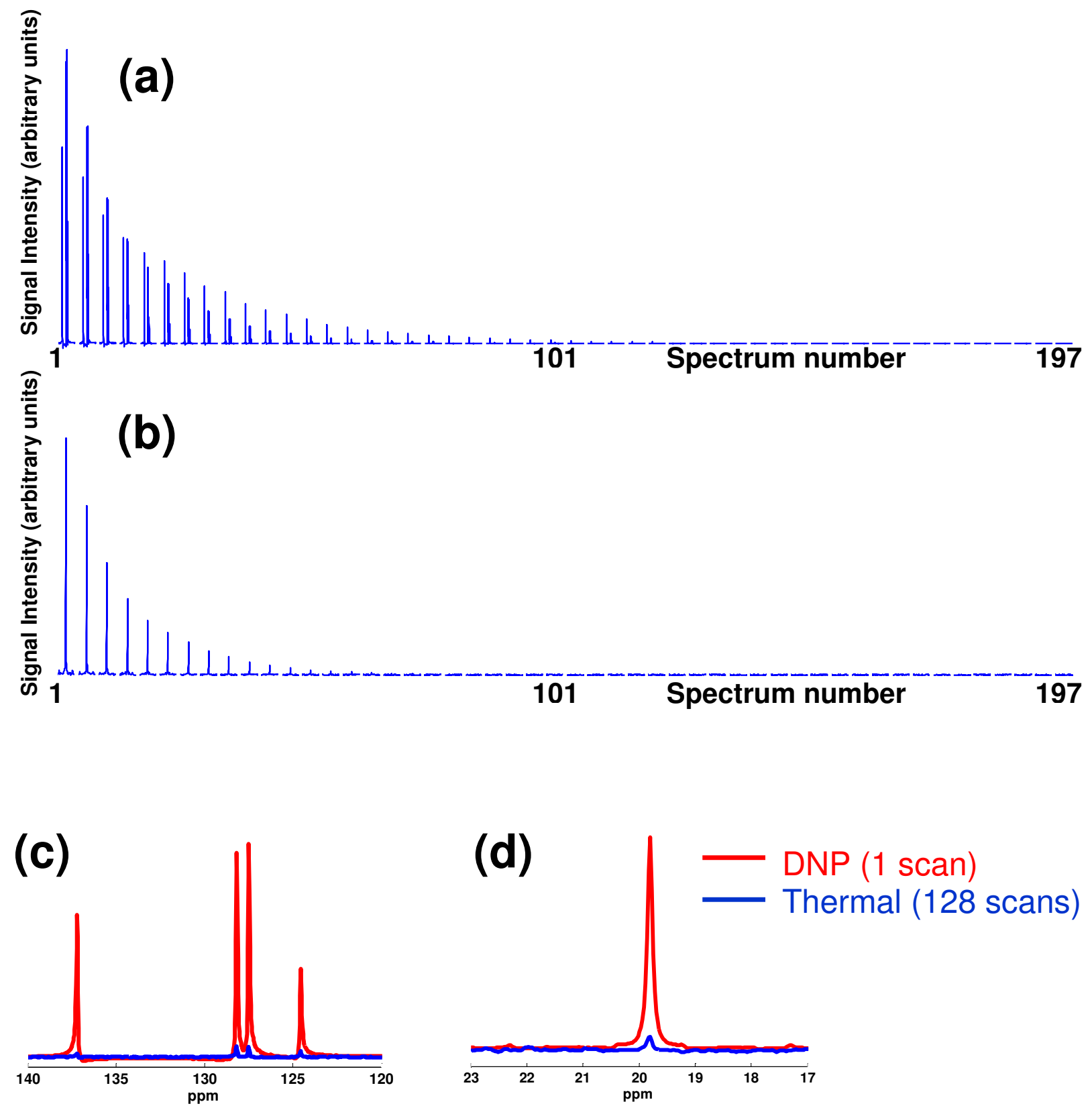

Figure S4. (a and b) Series of ${ }^{13} \mathrm{C}$ NMR spectra generated by a succession of small tip angle pulses following a dissolution experiment with a $100-\mu \mathrm{L}$ sample of $40 \mathrm{mM}$ BDPA in toluene. The sample was polarized at $93.965 \mathrm{GHz}, 100 \mathrm{~mW}$ microwave power, and $1.5 \mathrm{~K}$ for 90 minutes, followed by dissolution with $4 \mathrm{~mL}$ of methanol. A total of 200 spectra were collected; for clarity only every $4^{\text {th }}$ spectrum is shown. Successive spectra were acquired $1 \mathrm{~s}$ apart. In (a) each spectrum is zoomed in to the aromatic carbon region, and in (b) each spectrum is zoomed to the methyl carbon region. (c) Comparison of thermal and DNP-enhanced signal for the aromatic carbons of toluene. (d) Comparison of thermal and DNP-enhanced signal for the methyl carbon of toluene. In (c) and (d), 128 scans were collected in order to be able to see the thermal equilibrium signals. The enhancement factors are $\sim 2300$ and $\sim 1000$ for the aromatic carbons and the methyl carbon, respectively. 